\title{
RESEÑA
}

\section{EL AMOR Y LAS RELACIONES DE PAREJA EN LA MODERNIDAD: UN ANÁLISIS TRANSCULTURAL DEL LIBRO DE BECK Y BECK TITULADO “EL NORMAL CAOS DEL AMOR”}

\author{
Keilyn Rodríguez \\ Escuela de Antropología, Universidad de Costa Rica \\ San José, Costa Rica \\ Ministerio de Cultura y Juventud, San José, Costa Rica \\ KEILYN.RODRIGUEZ@ucr.ac.cr
}

\section{Introducción}

Según Rodríguez (2012), en el presente, el amor ya constituye un objeto de estudio en las ciencias sociales y afirma que la única manera en la cual podemos en la actualidad conocer cómo los grupos sociales están individualizando sus concepciones y prácticas amorosas es mediante la investigación empírica, donde la antropología puede aportar.

En este sentido, Smith (2001) señala que el asunto del amor romántico es una de las temáticas que ha interesado a antropólogos y a otros investigadores de la cultura desde Murdock en 1969 hasta el presente. Informa que se han realizado investigaciones que incluyen hasta 200 culturas con el propósito de identificar si el amor romántico es universal o bien, una condición propia de las culturas Euroamericanas, producto de la modernización y los procesos de individualización que conllevan. 

Smith (2001) refiere que diversos autores son de la opinión de que es importante entender las manifestaciones emic del amor romántico en todas sus variedades culturales. Además, refiere que Jankowiak y Fisher en 1992 encuentran que el amor romántico no es único de las culturas euro-americanas, sino que es un universal transcultural. En este sentido, es importante entender su definición en tanto se considera que el amor romántico es cualquier atracción intensa que envuelve la idealización del otro, sin un contexto erótico, con la expectativa de que la relación perdure por algún tiempo en el futuro.

Ahora bien, los sociólogos Beck y Beck (2001) se han ocupado del tema de las relaciones de pareja en su obra titulada "El normal caos del amor" (2001), la cual me ha generado una serie de interrogantes, que dan pie a este artículo. Las preguntas que surgen de esa lectura son: ¿qué tan transcultural es el normal caos del amor en las relaciones de pareja heterosexuales? ¿Qué reportan investigaciones en otros contextos culturales influidos por la modernidad, en relación con el planteamiento de Beck y Beck (2001) sobre el amor y las relaciones de pareja específicamente?

Debido a que el libro de "El normal caos del amor" se escribe en Alemania y se basa en la realidad de esa sociedad en particular, interesa conocer los resultados de investigaciones sobre el mismo tema en otras culturas, para compararlos y resolver las interrogantes planteadas. Así las cosas, los objetivos del artículo son:

1. Describir los planteamientos centrales de Beck y Beck (2001) respecto al amor y a las relaciones de pareja (roles de género y expectativas específicamente), para la determinación de los aspectos de comparación con otras realidades culturales insertas en procesos de modernización.

2. Analizar comparativamente los planteamientos sobre el amor y las relaciones de pareja del análisis de Beck y Beck (2001) con otros resultados de investigaciones en las sociedades urbanas de Nigeria, Costa Rica y los Estados Unidos de Norteamérica, vinculadas con procesos de modernización. 
Es importante aclarar que este documento no pretende establecer un estado de la investigación sobre el tema, sino comparar los planteamientos centrales del autor y la autora de "El normal caos del amor" con reportes de investigación sobre la temática, efectuados en nuestra sociedad costarricense, en Estados Unidos de Norteamérica (por ser una sociedad moderna diferente a Alemania) y en Nigeria por contar con un sistema de matrimonio totalmente distinto al alemán, pero estar inserta en procesos de modernización.

Ahora bien, se ofrece en el primer apartado una descripción general de los planteamientos centrales de Beck y Beck (2001). En el segundo apartado, se establece una comparación de los planteamientos señalados en el apartado anterior con los reportes de investigación sobre la temática en varias culturas. Por último, se expone una síntesis de consideraciones finales con el propósito de puntualizar la solución a las preguntas planteadas.

\section{El amor y las relaciones de pareja desde Beck y Beck (2001)}

En este apartado, interesa ofrecer un breve resumen de lo que el libro titulado "El normal caos del amor" plantea sobre el amor y las relaciones de pareja para la modernidad en Alemania. Si bien la autora y el autor señalan que se ha dado un cambio de la industrialización a la modernidad, en la concepción del amor y de los roles de las mujeres y los hombres, la manera en cómo el cambio se ha dado no es lo que interesa en este momento, sino, resulta relevante situarse en el presente y exponer la manera en cómo el autor y la autora explican las temáticas señaladas. 
El normal caos del amor se manifiesta en el cambio de la familia nuclear de roles tradicionales a más igualitarios y con el cambio en la biografía femenina hacia una individualización, tal y como el hombre ya la había logrado. Ahora bien, se entiende por individualización, la liberación de los roles de género familiar propios de la sociedad industrial para construirse una existencia propia a través del mercado laboral, de la formación y de la movilidad y si fuera necesario en detrimento de relaciones amorosas, familiares y vecinales.

El autor y la autora señalan que la conciencia de género femenina ha avanzado hasta lograr igualdad en derechos tradicionalmente masculinos, pero considero que ni las mismas sociedades modernas han logrado tal igualdad, en términos de equidad en los roles domésticos y participación social, según se evidenciará en las investigaciones que se presentan especialmente sobre la situación en Estados Unidos de Norteamérica.

Estos escritores afirman que en la actualidad se dan procesos sociales de aislamiento y de pérdida de sentido existencial; por esa razón, crece la añoranza por la familia como patria interior, como puerto en un mundo que se ha vuelto extraño e inhóspito. Así, cuanto menos significado tienen los vínculos tradicionales, tanto más importantes se vuelven las personas próximas en términos de bienestar físico y emocional.

Consideran que la lucha de los géneros es el drama central de nuestro tiempo y que el amor se vuelve más importante que nunca, puesto que en épocas anteriores, la vida de los seres humanos era determinada por un gran número de vínculos tradicionales, los cuales cumplían una doble función. Por un lado, estructuraban de manera rigurosa las posibilidades de elección del individuo; y, por el otro, ofrecían familiaridad y protección, sentido de pertenencia; la base de estabilidad e identidad interior.

Con la transición a la sociedad moderna, se da una individualización de gran envergadura, que consiste en un desprendimiento de los vínculos sociales históricamente construidos, de sus credos y formas de relaciones sociales. Esta disolución va acompañada de nuevas formas de concebir y actuar en el ámbito subjetivo. 
De esta manera, se presencia el comienzo paulatino de unas exigencias y obligaciones de una vida propia donde el individuo se ve confrontado con nuevos interrogantes y con una "pérdida de patria interior"; es decir con un aislamiento dentro del cosmos.

Este cambio en las relaciones con la naturaleza y con los seres humanos, debido a una gran apertura de los procesos educativos, confronta a las personas con preguntas que traspasan la lucha por la existencia, supone también la liberación de anteriores controles y obligaciones, una pérdida de estabilidad interior con el desencantamiento del mundo, y un aislamiento dentro del cosmos. Así, cuanto menos significado tienen los vínculos tradicionales, tanto más importantes se vuelven las personas próximas en términos de bienestar físico y emocional.

Las biografías femenina y masculina han cambiado y han seguido procesos diferentes, pero a la vez interconectados en términos de implicaciones mutuas. De esta manera, a partir de la década de los años 70 del siglo XX (aunque inicia paulatinamente a finales del siglo $X I X)$, la mujer se plantea su propia individualización, al igual que el hombre ya lo había hecho.

Uno de los aspectos que ha contribuido a esta individualización en la biografía femenina han sido los cambios en su acceso a la educación, pues le permite una desvinculación de los roles referidos únicamente a la vida familiar y, por lo tanto, un replanteamiento de sus aspiraciones y lugar en la sociedad. Sin embargo, tanto hombres como mujeres se encuentran atrapados entre los viejos patrones de comportamiento y los nuevos. La fémina, por su parte, se encuentra sola, pues reconoce que el varón no le puede dar el sentido y la orientación a su vida. Mientras, los hombres construyen un ideal femenino: la mujer independiente y a la vez con suficiente capacidad de adaptación a él.

La maternidad sigue siendo la "atadura" más fuerte al rol tradicional de la mujer; de hecho, las nuevas generaciones de sociedades modernas empiezan a plantearse si quieren asumirla o no. Por otra parte, el autor y la autora señalan que en la modernidad lo que mantiene unida a la pareja es el miedo a la soledad y las nuevas formas de familia tienden a ir y venir entre diversas familias temporales o a 
un sistema uniparental o unipersonal. Los matrimonios para toda la vida tienden a ser la excepción. La elección de pareja se hace libremente, lo cual trae nuevos riesgos y rupturas permanentes. La nueva pareja trata de construir espacios para una mejor vida de los que participen de ella. Sin embargo, algunas veces sucede lo contrario.

Debido a lo anterior, la búsqueda de la estabilidad personal va configurando una nueva comprensión del amor romántico. Se concibe bajo un modelo de amor duradero entre dos personas estrechamente relacionadas, que da contenido, arraigo y sentido a la vida. Mientras más referentes externos se pierden para la estabilidad, más se da una orientación hacia la relación de pareja en busca de seguridad ante un mundo que gira a velocidad vertiginosa.

Así, el matrimonio se convierte en una instancia central para la construcción de la realidad social; resulta ser un universo común de interpretaciones, valoraciones y expectativas sobre cotidianidades y grandes eventos mundiales. Es en el matrimonio, o en la vida de pareja, donde la imagen del mundo es reinterpretada, negociada y reafirmada permanentemente.

No obstante, ese diálogo buscado muchas veces fracasa y es roto, por lo que no sólo las esperanzas del amor, sino, sobre todo sus decepciones, remiten a la creciente individualización en la modernidad, en donde existen mayores posibilidades de elección en la cotidianeidad, lo cual se puede percibir como una sobrecarga y crece el potencial de conflictos en el matrimonio.

Ahora bien, el ideal del amor romántico está determinado en su fase inicial, como el desbordamiento de sentimientos gracias a la fascinación por el otro, el desconocido. Con el tiempo, este tipo de amor puede desaparecer y queda la desilusión de no poder prolongarlo eternamente. Otro de los aspectos que dificulta la relación de pareja es la diferente forma de concebirla por parte de los hombres y de las mujeres. Los primeros se enfocan en lo instrumental del amor y el matrimonio, mientras que las segundas se centran en los sentimientos y la cercanía interior o en el entenderse. 
Asimismo, muchas mujeres han rechazado ser la agencia de paz y armonía en el hogar y no solo esperan dar cariño, sentimientos y calor humano, sino también recibirlo. Por este motivo, se llega al caos del amor que el autor y la autora resumen como "queremos querernos, pero no sabemos cómo" (Beck y Beck, 2001).

Con la disolución de la familia como unidad económica, tal y como en la industrialización se concebía, se producen nuevas formas para asegurar la existencia, mediatizadas por el mercado del trabajo y relacionadas con la persona. Una de las transformaciones es la participación en el mercado laboral que requiere movilidad y presupone formación, y la otra es la lucha por el espacio propio, la búsqueda del yo y de la autorrealización que se manifiesta en el ámbito laboral y en la vida en pareja.

Beck y Beck (2001) señalan que en la sociedad individualizada, la relación con el otro género se complica, por lo que, para reducir el riesgo, se dan formas de comportamiento que incorporan intentos de autoprotección. Entre algunos grupos crece el miedo a comprometerse, la desconfianza ante cualquier forma de vinculación de pareja, así en lugar del amor por la pareja está el amor al hijo. De esta manera, aparece una nueva pareja: mujer e hijo, entre quienes se entabla un amor romántico que, según los autores mencionados, en esos casos sustituye al de la pareja.

En este contexto, es posible plantearse el divorcio: ante la falta de ponerse de acuerdo sobre el lugar de las aspiraciones de cada uno, ante la soledad irresuelta por falta de comunicación, ante las demandas del mundo laboral que dificultan la vida en pareja e imposibilitan la familiar, ante el desgaste en el tiempo del amor romántico, ante la no negociación de los roles de cada uno, ante el no encontrar el propio "yo" en el "vos".

Sin embargo, el autor y la autora plantean que existe una salida para el normal caos del amor: la negociación, la constante comunicación en torno a los puntos señalados en el párrafo anterior para continuar o terminar la relación. Lo que interpreto como una individualización intersubjetiva. 


\section{El amor y las relaciones de pareja desde otras investigaciones, en comparación con los planteamientos de Beck y Beck (2001)}

Interesa explicitar las conclusiones a las que otros investigadores en otras culturas han llegado sobre el amor y las relaciones de pareja y compararlas con la propuesta de Beck y Beck (2001). Se hace referencia a investigaciones en Costa Rica, Nigeria y Estados Unidos en Norteamérica, en ese orden.

Es necesario señalar que, a la vez que se exponen las investigaciones, se hace la comparación con la propuesta del autor y la autora de "El normal caos del amor", y se consideran las siguientes categorías de análisis:

Cuadro 1: Categorías de análisis y sus componentes para comparar la propuesta de Beck y Beck (2001) con otras realidades culturales

\begin{tabular}{|c|c|}
\hline Categoría & Componentes \\
\hline $\begin{array}{l}\text { Nuevas formas de } \\
\text { familia }\end{array}$ & $\begin{array}{l}\text { Familias temporales por rupturas permanentes } \\
\text { Familias uniparentales o unipersonales }\end{array}$ \\
\hline $\begin{array}{l}\text { Cambio en la } \\
\text { biografía femenina }\end{array}$ & $\begin{array}{l}\text { De roles tradicionales a igualitarios } \\
\text { Hacia una individualización de la mujer }\end{array}$ \\
\hline $\begin{array}{l}\text { Tendencia a la } \\
\text { individualización del } \\
\text { concepto del amor } \\
\text { romántico }\end{array}$ & $\begin{array}{l}\text { Rupturas y nuevas uniones en función de intereses } \\
\text { personales. } \\
\text { Mayor potencial de conflictos de parejas atrapadas entre el } \\
\text { viejo y el nuevo modelo } \\
\text { Ideal del amor romántico centrado en el desbordamiento } \\
\text { sentimental por el otro, que puede desaparecer con el } \\
\text { tiempo y que da la desilusión de no poder prolongarlo } \\
\text { Queremos querernos, pero no sabemos cómo }\end{array}$ \\
\hline
\end{tabular}




\section{Investigaciones en Costa Rica}

Con base en diferentes investigaciones, analizaré las categorías expuestas anteriormente para el caso de Costa Rica, particularmente en lo que se refiere a la cultura urbana.

\section{Nuevas formas de familia}

Por cada cuatro bodas, hay un divorcio. De 1994 a 1999, la cantidad de separaciones registradas se duplicó. Por otro lado, el Instituto Costarricense de Sexología con sus estudios muestra el gran vacío en la vida sexual de los costarricenses, donde el $90 \%$ de los costarricenses sufre de eyaculación precoz y solo 6 de cada 100 mujeres logran llegar al orgasmo (Varela, 2001a).

Adicionalmente, la autora refiere un cuestionamiento a la fidelidad como práctica del costarricense. Sin embargo, no se logra demostrar con datos claros este punto. Se afirma que el $40 \%$ de mujeres contagiadas por el VIH son esposas fieles y que 15.000 personas están contagiadas con sida, siendo la vía principal de adquisición del virus las relaciones sexuales no monógamas. Además, se comenta que pareciera que las mujeres durante el noviazgo suelen ser infieles.

Respecto a esta dualidad entre lo que la gente dice y sus prácticas reales, se puede explicar desde el planteamiento de Beck y Beck (2001), que el ideal del amor romántico y la familia está ahí en el discurso, pero en la práctica, el caos del amor está presente. La insatisfacción que se muestra desde la infidelidad y la cantidad de divorcios es realmente una evidencia clara del paso de un tipo de familia a otros. 
En este sentido, Vega (2001) señala que existe una gran diversidad familiar en Costa Rica. Indica que predominan los hogares nucleares conyugales (padre, madre e hijos) y, al igual que en otros países, este tipo de familia tiende a disminuir y aumentan los hogares uniparentales y unipersonales. Asimismo, afirma que uno de los factores que incide en el aumento del segundo y tercer tipo de familia son las separaciones y los divorcios. Sobre la cantidad de divorcios, estima que en 1997 el $52 \%$ de los jefes y $55 \%$ de las jefas de hogares uniparentales estaban separados o divorciados.

\section{Cambio en la biografía femenina}

La misma autora encontró que pareciera que en Costa Rica se está dando un cambio en los roles de género, donde, contrario a lo tradicional, el padre sin esposa o compañera tendría a su cargo el cuidado de sus hijos. Otro de los aspectos sobre roles de género en la vida de pareja es la aceptación de una mayoría en considerar que el hombre es el responsable de proveer lo económico, opinión más compartida entre las mujeres que entre los hombres.

Por otro lado, la experta da a conocer cómo entre las mujeres con mayor educación se dificulta la aceptación del hombre como jefe de hogar. Sin embargo, la tendencia es el ideal de llevar la jefatura del hogar entre ambos.

Resulta importante destacar que, en términos generales, Vega (2001) señala que los principales valores en la sociedad costarricense son la familia y el trabajo. Muestra el predominio de valores tradicionales, tales como que para los hombres lo más importante es el trabajo, y para las mujeres, la familia. Pese a que estas valoraciones disminuyen un poco cuando ellas tienen mayor nivel educativo. 
En síntesis, plantea que la familia se ve afectada por situaciones políticas y socio-económicas, está sujeta a cambios y tensiones, pero sigue siendo un valor central en las culturas costarricenses (a diferencia del desencanto con otras instituciones sociales). Considera que existe resistencia por el cambio que se requiere desde la familia, para afrontar los retos del mundo moderno con normas familiares que respondan a los cambios socio-económicos.

En relación con los cambios de roles de género que indica Vega (2001) para Costa Rica, resulta similar a lo que Beck y Beck (2001) plantean como parte de los cambios que se esperan en el paso a la sociedad moderna, aunque la nuestra diste de serlo, se puede notar, según los planteamientos de la autora, cómo la educación formal ha influido y creo que también los procesos de globalización que buscan homogenizar concepciones y valores a través de las nuevas tecnologías de la información y la comunicación.

Tendencia hacia la individualización del concepto del amor

El 11 de febrero de 2001, en la Revista Dominical, Varela (2001b) dio a conocer un estudio sobre el romanticismo, la atracción hacia el sexo opuesto y la fidelidad. En este sentido, expone que el $54 \%$ de las personas encuestadas están convencidas de que el amor a primera vista existe; un $58 \%$ de las mujeres entre 50 y 65 años nivel socioeconómico medio-bajo afirma que la inteligencia es más importante que la apariencia física, los hombres de nivel socioeconómico alto entre 25 y 29 les atrae la inteligencia y lo físico en igual proporción, solo 3 de cada 100 consideran que el dinero es un criterio para la plenitud. En términos generales, se encontró que las mujeres tienden más al romanticismo para elegir pareja que el hombre, pese a que la insatisfacción de la vida amorosa es mayor entre el género femenino $(9,6)$ que entre el masculino $(3,5)$.

Sobre la fidelidad, los resultados muestran que $15 \%$ indica que ha sido infiel en algún momento a su pareja, 2 de cada 100 es infiel ocasionalmente, 18\% no contestó y el $65 \%$ afirma ser fiel. 
La fidelidad es una característica que podemos asociar con la tendencia hacia la individualidad en la formas de concebir el amor romántico.

\section{Investigación en Nigeria}

\section{Nuevas formas de familia}

Smith (2001) realiza una investigación sobre el amor romántico y las relaciones de pareja entre los Igbo, una comunidad de Ubakala en Nigeria, África. Se ubica mayormente en zonas urbanas, la población es joven y con mucha influencia de los procesos de globalización.

El autor señala que después de la Segunda Guerra Mundial se da en África un resurgimiento de la literatura romántica, y es justo en ese momento cuando se registra históricamente el inicio del matrimonio moderno. Sin embargo, estos cambios están ocurriendo en las áreas urbanas, entre las elites y los grupos con mayor educación formal.

De esta manera, en la contemporánea sociedad de los lgbo, los jóvenes escogen sus parejas. Pese a que la mayoría de las relaciones maritales son negociables y basadas en el amor romántico como parte del proceso de individuación, el aspecto no negociable es la fertilidad y, por lo tanto, la descendencia. En esto, los africanos no solo abandonan las prácticas tradicionales a favor de las modernas, sino crean sus propios sistemas de matrimonio y organización familiar utilizando recursos del pasado y del presente, negociando las tensiones emergentes, y haciendo calzar las tradicionales con las modernas moralidades.

Respecto a la moderna sociedad de los Igbo, Smith (2001) señala que existe una constante tensión entre la dinámica del cortejo y la del matrimonio. Por un lado, el cortejo privilegia la naturaleza íntima y las expresiones de amor en la 
relación de la pareja, y fomenta la igualdad de géneros; mientras que el matrimonio refuerza la jerarquía patriarcal, la tendencia a continuar con los lazos y obligaciones hacia la familia extensa y la comunidad, privilegia la fertilidad y los roles de maternidad y paternidad.

El eje de la tensión señalada en el párrafo anterior es la continuidad de los valores asociados con la fertilidad y el parentesco, siendo la fertilidad la variable dependiente. Lo anterior es fundamental, pese a que en apariencia la selección de pareja, el matrimonio y la familia están cambiando hacia formas descritas como modernas desde una visión euroamericana. Ahora bien, los patrones culturales de cortejo y matrimonio difieren un poco entre la ciudad y los pueblos.

Las parejas que se establecen en la ciudad toman mucho tiempo informándose y conociéndose sobre sus respectivas familias y comunidades en el proceso de matrimonio. En este sentido, la persistencia del valor de la fertilidad se explica en parte por la importancia de los grupos de parentesco, hasta en la moderna África.

El sistema de parentesco de los Igbo es patrilineal y el matrimonio es exógamo (siempre y cuando sea entre lgboes), pues es importante la creación de alianzas fuera de la comunidad. Tanto el sistema tradicional como el moderno supone matrimonios con la presencia de cientos de parientes del novio y la novia, es imposible casarse sin el consentimiento y presencia de la familia. Los criterios familiares de aprobación de una pareja son según clase y etnia, es muy difícil que acepten a alguien que no sea Igbo; y la distancia de residencia del novio respecto de la novia es un criterio que aplica la familia de ella. Lo anterior debido a que el sistema de residencia es patrilocal y supone que ella se iría a vivir demasiado lejos de su propia familia; mientras que para la familia del novio no importa, pues el hombre y los niños se quedan con ellos.

Por otro lado, Smith (2001) hace referencia a una de las producciones cinematográficas más populares del momento entre los Nigerianos, se titula "Taboo" y trata de una joven Igbo procedente de una familia muy adinerada que se enamora de un Osu (es una etnia descendiente de esclavos, actualmente es un estatus abolido legalmente) a quien conoce en la universidad. La familia de la 
novia crea una serie de estigmas sobre Osu, afirmando que está contaminado y es peligroso. La situación presentada en el filme es muy propia de la vida actual de Nigeria, donde los padres comúnmente no aceptan la boda de su hija con un Osu porque se daría un descenso de estatus en la filiación de los hijos de la mujer, pues pasaría a ser Osu; a la vez que no sería una alianza provechosa.

En la película, se muestra el anonimato en la vida citadina y la mezcla cultural que ella envuelve. Sin embargo, este anonimato étnico es imposible mantenerlo durante una boda, debido a las implicaciones sociales relacionadas con la ceremonia. En todo caso, la historia del Osu y la lgbo concluye con un final heroico para el muchacho. El Osu muere en una valiente confrontación con unos malhechores sin concretar la unión con su amada, la cual llora la pérdida de su amor. El autor señala que al igual que "Taboo", existen otros filmes nacionales que refuerzan la idea del amor romántico y valorizan la individualidad. Así, la tensión entre lo moderno y lo tradicional continúa.

Ahora bien, respecto de la ceremonia, es usual que se realicen dos: la tradicional y también la cristiana. Así, las prácticas religiosas cristianas también han contribuido a generar cambios en las relaciones de pareja. Debido a que la fertilidad es muy importante, la mayoría de parejas, tras casarse, deciden tener hijos, pues más que una opción personal, es un compromiso familiar. La larga espera para concebir es vista socialmente como infertilidad. Así, la fertilidad disminuye las posibilidades de divorcio socialmente aceptado, mientras que la infertilidad hace que una separación sea totalmente permitida.

Con respecto a la infidelidad antes del matrimonio, es más aceptada (aunque trae sus problemas) para la mujer, mientras que un hombre que engañe a su prometida difícilmente se casa con ella.

Todo cambia una vez casada la pareja; a la mujer que sea infiel le espera un divorcio socialmente aceptado y corre el riesgo de perder a sus hijos, ya que pertenecen a la familia del padre. En el caso de la infidelidad del esposo, la mayoría de esposas sabe que su marido tiene una amante, pero mientras él y su amante cumplan con los limites sociales estimados (que la amante no llame a casa, que no sean vistos en público, que ella no conciba hijos de él, que no gaste 
mucho dinero en ella, que la relación no dure mucho tiempo) y él, con los deberes económicos familiares, la mujer no se podrá divorciar de él, aunque quisiera y deseara que le sea fiel.

\section{Cambio en la biografía femenina}

Smith (2001) señala que el rol de la mujer tiende a cambiar entre las nuevas mujeres profesionales (abogadas, doctoras, y similares.) Igbo, puesto que el nivel educativo y sus recursos económicos individuales les permiten otro estatus social, una incipiente tendencia a la independencia y a niveles de decisión familiar diferente, lo que de alguna manera influye en la fidelidad de su esposo.

La tensión a la que se refieren la y el autor, entre los patrones viejos y los nuevos, sobre los roles de género y el amor en las parejas, sigue presente en el caso de Nigeria; aunque las formas patriarcales de dominación han cedido unos espacios a ciertas mujeres para decidir sobre su pareja, previo al matrimonio, sigue manteniéndose la dominación masculina. La influencia de los medios de comunicación en este sentido refuerza el cambio hacia formas modernas más individualistas en la relación.

\section{Tendencia a la individualización del concepto del amor}

Uno de los cambios que introduce la modernización y la individualización que señalan Beck y Beck (2001) es el espacio socialmente aceptado para el amor romántico y la intimidad en las relaciones de pareja; en el caso de Nigeria, se nota de manera incipiente este aspecto, en tanto que se está dando un cambio cultural en torno a formas modernas de seleccionar al cónyuge.

Smith (2001) expone cómo la moderna sociedad Africana está sufriendo cambios, pues los jóvenes están negociando una transición en la forma de seleccionar su pareja hacia criterios; tales como, el amor romántico, el compañerismo y la intimidad emocional, pese a conservar los valores tradicionales de la descendencia y la fertilidad. 
En este sentido, el experto indica que en esa cultura existe una larga historia del amor romántico que constató en los testimonios personales y en las historias ancestrales, al igual que en otras investigaciones sobre el tema que datan desde los años 70. Encuentra que muchas personas confiesan que se casaron con personas de quienes no estaban enamoradas. Se presentan registros de una larga tradición del amor romántico desde antes que se iniciara su aceptación como criterio para elección de pareja. La existencia de este tipo de amor también se registró en los textos sobre concubinato en la sociedad Igbo tradicional. En este caso, hombres y mujeres tenían un acuerdo significativo e institucionalizado sobre cierta libertad sexual extramarital, aspecto relacionado con el amor romántico.

\section{Investigaciones en Estados Unidos de Norteamérica}

\section{Nuevas formas de familia}

Martín (2001) afirma que actualmente existen actitudes ambivalentes sobre el matrimonio; gran aceptación del divorcio y arreglos no tradicionales de cohabitación en la pareja y más aceptación de las relaciones sexuales prematrimoniales que en el pasado. En este contexto, el autor se interesa en examinar las actitudes de las adolescentes sobre el matrimonio y su relación con la actividad sexual premarital y la cohabitación.

Se expone que desde 1960, en Estados Unidos de Norteamérica, la cohabitación se ha convertido en una alternativa al matrimonio. En 1970, el censo nacional reportó 523.000 parejas que vivían juntas, y en 1996, 4 millones de parejas. Para 1998, se consideró que un cuarto de la población estadounidense entre los 25 y 34 años cohabitaba y que la mayoría de la gente contaba con una relación fuera del sistema del matrimonio antes de casarse.

Los acuerdos de convivencia son vistos como formas convenientes de contar con las ventajas de una relación íntima sin que medie un compromiso de 
larga duración. Considero que este fenómeno podría tener relación con que el periodo estimado para casarse se ha alargado en la vida de los jóvenes, por intereses sociales, tales como la educación. Otras razones que señala el autor es que los adolescentes, expuestos a altos niveles de conflicto entre padres y al divorcio, tienden a optar por cohabitación antes del matrimonio, y los padres divorciados tienen a la convivencia inmediatamente después de la separación, lo cual influencia las actitudes sobre el matrimonio de sus hijos adolescentes.

Pese a lo anterior, el porfesional expone que de las parejas que escogieron vivir juntas antes de casarse, el $50 \%$ más de las que no cohabitaron antes del matrimonio se divorcia. Sobre este fenómeno, se han planteado diferentes teorías. El Institute for American Values afirma que este fenómeno obedece a que la tendencia actual hacia el matrimonio y el nuevo matrimonio ha modificado las actitudes sociales sobre la unión libre y el sexo premarital (Martín, 2001). Otras investigaciones consultadas por el autor sugieren que el gran aumento de aceptación de la unión libre no está en contradicción con el matrimonio, pero se relaciona con la búsqueda de mayor seguridad y estabilidad.

Unido al fenómeno de las relaciones sexuales premaritales y la aceptación de la cohabitación prematrimonial está el caso del aumento en la cantidad de madres solteras que de 1980 a 1997 creció en un 60\%, llegando a ser de 10 millones.

Respecto a los adolescentes y a su sexualidad, se indica que se enfrentan, en términos generales, con cuatro estándares sobre el comportamiento sexual premarital:

1. La abstinencia

2. Un estándar doble: permite a los hombres, pero no a las mujeres disfrutar de actividad sexual con impunidad

3. Actividad sexual con afecto

4. Actividad sexual basada en el deseo físico solamente

Entre adolescentes, se muestra una creciente aceptación hacia la actividad sexual prematrimonial, si la relación es con alguien a quien se ama. Sin embargo, 
también una minoría acepta la posibilidad de tener relaciones sexuales sin una relación larga.

En comparación con los planteamientos de Beck y Beck (2001), se puede exponer lo siguiente:

- Martín (2001), Beck y Beck (2001) coinciden en la gran diversidad de tipos de familias que en cada sociedad moderna existen.

- Las contradicciones entre el discurso y la práctica de la igualdad de roles en la esfera doméstica serían una manifestación de las tensiones producidas por la modernidad con el mayor acceso de la mujer a la educación formal y a la participación en el ámbito familiar. Lo que sí queda claro es que en la cultura estadounidense la participación masculina en roles tradicionalmente femeninos en la vida doméstica no muestra la igualdad de roles de la sociedad moderna que supone una lectura de los expertos sobre el tema.

- Sobre la nueva pareja madre-hijo que refieren Beck y Beck (2001), Martín (2001) señala que para 1997 había, en EE.UU., 10 millones de madres solteras. Lo que no queda claro es en qué porcentajes se podría decir que el hijo viene a ser la pareja de la mujer y cuál sería el porcentaje de las mujeres que siguen esperando la realización de su amor romántico con una persona adulta.

- Un aspecto que señalan los autores es la construcción de mecanismos de autoprotección en las sociedades modernas; en este sentido, también se refieren a la pareja madre-hijo. De esta forma, según la investigación de Martín, podría decirse que la unión libre o convivencia tiene un sentido de autoprotección ante el fracaso de las relaciones románticas, en tanto no implica socialmente un vínculo de por vida; y en muchas oportunidades, una forma de probar si funcionaría un matrimonio de larga duración. Al igual que lo señalan Beck y Beck, Martín afirma que estos intentos no suelen ser muy fructificantes, pues de los matrimonios que cohabitaron antes de casarse, el $50 \%$ se divorcia.

- En relación con lo anterior, Martín (2001) logra identificar un patrón cultural importante: afirma que la mayoría de adolescentes que tienden a optar por la unión libre procede de hogares cuyos padres tenían conflictos de pareja y divorcios complicados. Además, logra establecer estándares que son los 
referentes de los adolescentes para la toma de decisiones sobre las relaciones sexuales a su edad. Esto obliga a cuestionar el concepto de la individualización que expone la modernidad como una total libertad de decisión respecto a las relaciones de pareja y del amor, pues existen ciertos marcos de referencia que parecieran determinar en alguna medida estas decisiones; entre ellos, la biografía que tiene un sentido socio-históricamente determinado y la hibridación de la modernidad con las culturas particulares. Estos marcos de referencia ofrecen una gama de posibilidades para escoger, y sería ingenuo no considerarlos en la toma de decisiones.

\section{Cambio en la biografía femenina}

Botkin (2000) da a conocer un estudio longitudinal sobre el cambio en las expectativas de los roles en el matrimonio, el cual inicia en 1961 y termina en 1996. Este se realizó entre estudiantes universitarios de la Universidad Estatal Land-Grant del sureste de Estados Unidos con estudiantes blancos estadounidenses, utilizando siete sub-escalas, ellas son: autoridad, cuidado de los niños, oficios domésticos, características personales, participación social, empleo y soporte económico. En estas se manejaron tres niveles de mayor a menor igualdad. Se identificó que el nivel educativo de los estudiantes no fue un factor determinante en los datos arrojados.

Además, indica que uno de los aspectos sociales que ha impactado las expectativas femeninas respecto a los roles del matrimonio es el aumento de las distancias de tiempo de la vida con los padres y el momento de inicio del matrimonio, pues estas mujeres salen de casa, viven independientemente, trabajan y estudian antes de casarse.

Otro de los factores de cambio es el movimiento femenino desde la década de los años 70 hasta la de los 80 , pues se ha enfocado en la flexibilidad de los roles de género. De la década de los 80 a la de los 90, una serie de aspectos influencia la realidad de mujeres y hombres; el enfoque en la igualdad de derechos entre géneros, la emergencia del antifeminismo, los movimientos profamilia, el 
énfasis en los conocidos "valores familiares" que hacen un llamado a la familia nuclear tradicional (caracterizada por la división tradicional de roles; la mujer encargada de la casa y el hombre como proveedor) y la emergencia de disponer de tiempo para ser mamá desde el ámbito laboral.

Desde 1969 hasta 1972, se encontraron cambios significativos hacia expectativas más igualitarias en todas las sub-escalas, excepto la de autoridad. Asimismo, desde 1972 hasta 1996, los únicos cambios significativos fueron en las sub-escalas de autoridad, oficios domésticos y cuidado de los niños.

Así, de 1990 a 1996, se encontró según la escala de menor a mayor igualdad que:

1. Existía mayor igualdad que en los dos puntos 2 y 3 en las sub-escalas de oficios domésticos, autoridad, cuidado de los niños y educación.

2. Existía mayor igualdad que en el punto siguiente (el 3) en las sub-escalas de empleo, soporte económico y oficios domésticos.

3. Existía menos igualdad respecto a los dos puntos anteriores, en las subescalas de características personales y participación social.

En términos generales, la tendencia desde 1961 hasta el momento es el cambio de roles hacia una igualdad de responsabilidades en la vida familiar. De esta manera, se muestra cómo no existe una tendencia hacia valores tradicionales de los roles de género en la pareja, a excepción de la sub-escala de cuidado de los niños que desde 1984 lentamente tiende a bajar de 95,9 a 91,6, lo cual para el autor es significativo en lo que respecta a la disminución de las expectativas sobre la responsabilidad paterna del cuidado de los hijos.

Otra investigación sobre los roles de género en la vida de pareja en Estados Unidos la realiza Greenstein (1996). Este autor propone que para entender cómo emerge en la actualidad la división de las tareas domésticas, es fundamental comprender la interacción entre la ideología de las esposas con la de sus esposos. Su estudio es empírico con 2.719 parejas casadas y 13.017 adultos y lo realiza con el National Survey of Families and Households.

El autor señala que inclusive en las parejas donde ambos creen en la igualdad, en la cotidianidad, los hombres participan muy poco de las tareas 
domésticas. De hecho, esposas trabajadoras dedican $72 \%$ del total de horas que están en casa, y las esposas que están en casa dedican el $82 \%$, siendo la diferencia muy poca. Además, se indica que de las tareas domésticas tradicionalmente masculinas, el hombre está efectuando el $70 \%$, y de las tradicionalmente femeninas, la mujer está realizando el $75 \%$.

En este sentido, las estadísticas ofrecidas en la investigación anterior nos obligan a remitirnos a las prácticas reales que nos señala este estudio, a diferencia del discurso que capta una encuesta.

Además, indica que el matrimonio es un escenario para validar las identidades masculina y femenina, mediante comportamientos que reflejan sus ideologías de género. Así, un hombre que considere que lo masculino es relegar las labores domésticas a la mujer, lo reflejará en la vida doméstica. Mientras que un hombre que considere que lo masculino es compartir igualdad de responsabilidades en las tareas, tratará de llevarlo a la práctica.

\section{Tendencia individualista del concepto del amor}

PewResearch Center Survey (2010) arrojó datos que muestran que conforme pasa el tiempo, las personas estadounidenses se están casando menos. Informan que entre las personas solteras, solo el $61 \%$ le gustaría casarse, el $27 \%$ no está seguro y el $12 \%$ no desea hacerlo. Este último $39 \%$ refleja una nueva tendencia propia de la modernidad, pues en sociedades tradicionales casarse es la opción; no casarse o cuestionarse, esa posibilidad no existe.

Adicionalmente, se evidencia la tendencia hacia la individualidad en las nuevas formas de familia que las personas refieren. La encuesta muestra que se define como familia a los siguientes tipos:

- Familias uniparentales

- Pareja heterosexual no casada con hijo(s) o hija(s)

- Pareja gay o lesbiana con hijo(s) o hija(s)

- $\quad$ Pareja casada sin hijos e hijas o con hijo(s) e hija(s) 
Si bien la familia no es la unidad de estudio, sino las relaciones de pareja, interesa destacar el reconocimiento social de la pareja gay o lesbiana como una forma de unión socialmente identificada.

Por otro lado, para este análisis, resulta interesante el trabajo de Acevedo y Aron (2009) quiénes examinan la posibilidad de que el amor romántico (con intensidad, compromiso e interés sexual) pueda existir en las relaciones de pareja de largo plazo. Señalan que el componente de "obsesión" típico del amor romántico se encuentra en la etapa temprana de la relación y que puede y debe existir en matrimonios de larga duración, y se asocia con la satisfacción marital, el bienestar y la autoestima alta. Sin embargo, la obsesión o manía por la otra persona genera satisfacción solo a corto plazo; si se sostiene en el tiempo, genera insatisfacción marital, depresión y disolución del matrimonio. De esta manera, la obsesión junto con el amor romántico correlacionó positivamente para relaciones de corto plazo y negativamente en las relaciones de largo plazo. En este sentido, la obsesión en la relación de pareja es una tendencia individualista que perjudica la relación de largo plazo.

\section{Consideraciones finales}

Definitivamente, es posible hablar de un normal caos del amor en las relaciones de pareja, en tanto las sociedades sufren cambios y coexisten sistemas tradicionales con los modernos, reflejándose estos procesos de hibridización en la vida cotidiana y, por lo tanto, en relaciones de pareja y del amor. Se notó la gran cantidad de divorcios en Alemania, Estados Unidos de Norteamérica y Costa Rica; y en el caso de Nigeria, el gran porcentaje de esposos infieles. Se puede decir que la familia está en un proceso de cambio y el sistema anterior (bilateral o monogámico y patriarcal) está en crisis, lo que supone la reelaboración de esta institución en el ámbito mundial, pero no hacia unas formas determinadas y particulares, sino hacia formas inimaginables desde solo una perspectiva cultural, no individualizadas en todas las dimensiones de la vida social, pero sí 
determinadas socio-históricamente por las culturas particulares y por los procesos de reestructuración generados por el mercado mundial, y por el acceso y desarrollo de las nuevas tecnologías de la información y la comunicación.

Los procesos de globalización acelerados junto a los procesos de apertura a un mercado internacional exponen a las culturas a la misma realidad externa. Sin embargo, las formas locales de asumirlo y las mezclas que se dan de lo externo y lo propio no pueden ignorarse, por eso no existe la modernidad pura, ni una única forma de ser individualizado o de re-significar el sistema patriarcal.

Así, la individualización en la modernidad debe comprenderse en el contexto de la biografía de hombres y mujeres quienes tienen un sentido sociocultural, y en el amor romántico que no es propio de occidente, tal y como Smith (2001) lo indica. No obstante, en los estudios consultados se puede notar cómo el sistema patriarcal en sociedades no occidentales, especialmente patrilineales como Nigeria, asume nuevas formas respecto al amor y el romanticismo, en un intento de preservación ante la influencia de las concepciones modernas, pero manteniendo la esencia de la tradición patriarcal, lo que nos plantea el reto de conocer las nuevas formas de dominación femenina en las diversas culturas.

Es posible considerar un cambio en las biografías femeninas en todos los países registrados, pese a que se dan en diferentes direcciones. Asimismo, es posible notar cómo la maternidad y los roles asociados con ella son aspectos que afectan de manera diferente la tendencia hacia la igualdad de géneros. En este caso, muchas de las mujeres en sociedades europeas han optado por no ser mamás y han sido aceptadas culturalmente, mientras que este planteamiento es inimaginable en la moderna Nigeria.

Además, un aspecto importante que ha generado cambios centrales en la biografía femenina es el nivel educativo. Para el caso de Costa Rica, Vega (2001) concluyó que mientras mayor es el nivel educativo de la mujer, menor es la aceptación del hombre como jefe del hogar. Por el contrario, en el estudio de Botkin (2000), que se efectúa solo en el ámbito universitario en Estados Unidos de Norteamérica, se encuentra que los criterios de los estudiantes no varían según el nivel educativo. 
Pese a que ambos resultados parecieran contradictorios, creo que no lo son, por el contrario, pareciera que existe un tope de influencia de la educación formal respecto a los cambios en los roles de género, y que esas variantes sugeridas por esta educación son asumidas en la vida cotidiana, generando una nueva cultura entre los estudiantes y profesionales. Ahora bien, este cambio no es tan radical, pues la investigación de Botkin (2000) muestra que la igualdad no es total y la investigación de Greenstein (1996) evidencia que en la esfera doméstica, los roles siguen siendo tradicionales.

En cuanto a cambios en los roles propios de la biografía femenina y masculina, se consideran muy interesantes los resultados de todas las investigaciones, pues, si bien, en algunos campos se tiende a la igualdad, en última instancia, el dominio del sistema patriarcal se mantiene. Así, Botkin (2000) reafirma que el concepto de autoridad en Estados Unidos privilegia al hombre sobre la mujer. Smith (2001) en su investigación en Nigeria demuestra cómo se incluyen criterios de selección de pareja que privilegia el amor romántico y las relaciones personales de pareja en el cortejo, pero después, en el matrimonio, prevalece el patriarcal basado en la fertilidad y pertenencia familiar; y en el caso de Costa Rica, Vega (2001) afirma que la tendencia de las familias es a considerar los roles tradicionales de la mujer y el hombre.

Así, con base en los estudios registrados se concluye que existen modernas formas culturales de manifestación del sistema patriarcal, con una notoria tendencia hacia la ideología de la igualdad respecto a las responsabilidades en las tareas de la vida doméstica y en las profesiones, los trabajos y oficios, aunque en el fondo, el sistema patriarcal lucha por sobrevivir y mantener formas de control del hombre sobre la mujer en las prácticas cotidianas. 
Otro de los aspectos comunes en las investigaciones es la diferencia de los resultados encontrados en los estudios que se centran en las opiniones de la gente, y los resultados que son más externos y remiten a prácticas reales sobre el mismo tema. Esta diferencia muestra datos opuestos para el caso de Costa Rica, donde se contradice la práctica y el valor de la fidelidad, con el matrimonio para toda la vida; y en el caso de Estados Unidos de Norteamérica, donde las concepciones sobre la igualdad de género se contradicen con el tiempo real que los hombres dedican a labores domésticas, en relación con las mujeres.

En otro sentido, uno de los problemas centrales que trae consigo el matrimonio socialmente establecido para toda la vida es la infidelidad. A su vez, la infidelidad implica riesgos, especialmente en cuanto al contagio del VIH. Esta problemática se registra en Nigeria y Costa Rica claramente en los reportes de investigación estudiados. Sin embargo, la monogamia por plazos tampoco garantiza la no-propagación del virus.

Vale rescatar, en tensión con lo anterior, que entre alemanes, nigerianos, costarricenses y los estadounidenses existe la tendencia a ver al matrimonio como una relación que debe perdurar y ser estable, pese a los altos niveles de infidelidad y de divorcio.

¿Qué tan general es el caos del amor en las relaciones de pareja? En la sociedad moderna posindustrial estadounidense, cada 15 segundos una mujer es golpeada y la mayoría de las veces por un compañero íntimo (FNUAP, 2000). Esto sucede en la moderna nación de occidente ¿Será un problema de la modernidad o de la tradición? Con base en las investigaciones revisadas en este artículo, creo que es necesario plantearse nuevas interrogantes. Los estudios deben dar cuenta de las formas de significación y prácticas culturales sincréticas (pues la modernidad pura no existe) que se ponen en escena en la actualidad, que tienen nuevos sentidos y formas de perpetuar el dominio de unos sobre otras ¿Qué significa ser mujer y ser hombre en las sociedades híbridas actuales, sea Alemania, Costa Rica, Nigeria o Estados Unidos de Norteamérica? ¿Es suficiente la individualización y la igualdad de roles para que hombres y mujeres vivan en paz, armoniosamente y se establezcan relaciones humanas solidarias y justas? 
La Internet ofrece nuevos escenarios para el amor y el romanticismo, los cuales deben conocerse para descifrar cómo esos mundos virtuales inciden en los significados asociados con los roles de género en las relaciones de pareja. ¿Cómo conviven y se implican los "love bits", o "match" por chateo o con bases de datos, un "cyberkiss", el "cyber sex", los "access romance and control and escape", o los "hottest places" con las prácticas de la vida y con las identidades de hombres y mujeres que en la cotidianeidad se aman, se casan, hacen familias y siguen creyendo en ello?.

\section{Referencias bibliográficas}

Acevedo, B. y Aron, A. (2009). Does a Long-Term Relationship Kill Romantic Love?. Review of General Psychology, 13(1), 59-65.

Beck, U. y Beck, E. (2001). El normal caos del amor. España: Ediciones Paidos Ibérica y Editorial Piados, SAICF.

Botkin, D. (2000). Changing Marriage Role Expectations: 1961-1996. Sex Roles: a Journal of Research, 42(9-10), 933-942.

Choudhury, M. (1996). A Theory of Social Systems: Family and Ecology as Examples. Kybernetes, 25(5), 21-37.

Greenstein, T. (1996). Husban's Participation in Domestic Labor: Interactive Effects of Wife's and Husband's Gender Ideologies. Journal of Marriage and theFamily, 58(3), 585-595.

Fondo de Población de las Naciones Unidas (2000). Vivir juntos, en mundos separados. Estado de la población mundial. Estados Unidos de Norteamérica: Prographics. 
Martin, P. (2001). Adolescent Premarital Sexual Activity, Cohabitation, and Attitudes Toward Marriage. Adolescence, 36(143), 601-609.

Matute, R. (2002). Encuesta UNIMER-La Nación: Vida buena nos motiva. La Nación. Recuperado el 13 de abril de 2013, dehttp://wvw.nacion.com/In_ee/2002/agosto/04/pais1.html\#arriba.

Pew Research Center Social and Demographic Trends Project (2010). Thedecline of marriage and rise of new families. Recuperado el 1 de junio de 2013, dehttp://pewsocialtrends.org.

Rodríguez, T. (2012). El amor en las ciencias sociales: cuatro visiones teóricas. Culturales, 8(15), 155-180.

Smith, D. (2001). Romance, Parenthood, and Gender in a Modern African Society.Ethnology, 40(2), 129-151.

Kakuchi, S. (2002). Debate Over Surnames Upsets Old Gender Roles. Journalism and Comunication for Global Change. Recuperado el 13 de mayo de 2013, de http://www.ipsnews.net/2002/10/rights-japan-debate-over-surnamesupsets-old-gender-roles/.

Varela, I. (2001a). Amor a la tica. Revista Dominical. Recuperado el 10 de enero de 2013, de http://wvw.nacion.com/dominical/2001/febrero/11/dominical0.html. 
Varela, I. (2001b). Con cautela. Revista Dominical. Recuperado el 10 de enero de 2013, dehttp://wvw.nacion.com/dominical/2001/febrero/11/con.html.

Vega, I. (2001). "Las familias costarricenses en el contexto del nuevo milenio". Realidad familiar en Costa Rica. En I. Vega y A. Cordero (comps), Realidad Familiar en Costa Rica. Aportes y desafíos desde las Ciencias Sociales (pp. 199-220). San José, Costa Rica: FLACSO, UNICEF, Instituto de Investigaciones Psicológicas-Universidad de Costa Rica. 